\title{
A New Device for Repositioning the Premaxilla in Complete Bilateral Hefit Lip and Palate
}

Thimma Reddy BV', Vasavi Lakshmi $K^{2}$, Venkata Yudistar P' $^{1}$ Nandagopal V ${ }^{3}$

'Department of Pediatric and Preventive Dentistry and ${ }^{3}$ Department of Oral and Maxillofacial

Surgery, Mamata Dental College, Giriprasad Nagar, Khammam; ${ }^{2}$ Department of Pediatric

and Preventive dentistry, Meghna Institute of Dental Sciences, Nizamabad, Andhra Pradesh.

Abstract:

Bilateral cleft lip and palate often poses a problem to the surgical repair due to the anterior placement of the premaxilla which results in tension at the suture line. To facilitate the ease in surgical repair, nasoalveolar molding extends a helping hand in retracting the premaxilla and finer scar forms when a surgical incision heals under less tension. This article provides an insight of new appliance design which works on the Latham's appliance principles. The appliance utilizes an acrylic splint cemented on the premaxilla and alveolar portion of the palate, used to reposition the protruded premaxilla in child who reported late with primary teeth.

Key words: Cleft Lip, Cleft Palate, Deciduous Tooth, Sutures, Wound Healing.

\section{Introduction}

Cleft lip and palate are disfiguring and cause great psychological trauma to family and child. It is a congenital malformation with an overall prevalence rate of 2.0/1000 live births. For centuries, surgeons have recognized the challenges; the main obstacles to the lip repair being the protruding premaxilla and the deficient or absent columella making the nose tip flat [1]. In BCLP cases with protruded premaxilla, palatal movement through an intervention called pre-surgical infant maxillary orthopedics can be done which is an adjunctive neonatal therapy for the correction of BCLP $[2,3]$. McNeil (1950) popularized early maxillary orthopedics in CLP [4]. Georgiade and Latham described an intraoral fixed appliance with a palatal expansion component and a pin placed into the premaxilla for premaxillary retraction. The premaxilla is retracted by elastic chains attached to a pin placed through the premaxilla just anterior to the premaxillovomeral suture [5]. Later in 1990 Millard and Latham modified appliance with 4 intermaxillary pins, one pin of transmaxillary anchorage and an expansion mechanism in the palatal processes activated through elastomeric chains [6]. Later many modifications of PNAM appliances were developed and these were broadly grouped under active, semiactive and passive depending on force exerted by appliance on alveolar segments. The appliance to be used is decided after a proper evaluation of the case [7]. A case of BCLP is presented in which

\section{Corresponding Author: Dr. K. Vasavi Lakshmi}

Email: vasavi.bds@gmail.com

Received: March 7,2016 | Accepted: June 4, 2016 | Published Online: August 5, 2016

This is an Open Access article distributed under the terms of the Creative Commons Attribution License (creativecommons.org/licenses/by/3.0)

Conflict of interest: None declared | Source of funding: Nil | DOl: http://dx.doi.org/10.17659/01.2016.0087 
a modified noninvasive appliance was used as a part of presurgical orthopedics for the retraction of premaxilla.

\section{Case Report}

A 19 months old boy was referred from oral and maxillofacial surgery with complete bilateral cleft lip and palate and markedly protruded premaxilla. Orofacial examination revealed a non-syndromic BCLP (Veau Classification, type IV) with protruded premaxilla [Fig.1]. Intra-oral examination revealed primary teeth 51,61 , 54,64 in maxilla and $71,81,72,82,74,84$ in mandible. There was sufficient space to retract the premaxillary segment; therefore, it was decided to use a modified premaxillary repositioning appliance. We planned for preliminary impression under general anesthesia with elastomeric impression material. The appliance design consists of three acrylic parts, premaxillary acrylic cap with bilateral stainless steel hooks in the most lateral aspect, directed mesially and two palatal acrylic shelves with hooks of 20 guage stainless steel wire were placed in deciduous canine region and were attached by coffin spring [Fig.2(A)]. The appliance was designed to have retentive clasp around two primary incisors and two first primary molars for added retention. Unitek TM TAD Constant Force Coil Spring $3 \mathrm{~mm}$, light Force (150 g) on right side and 6 $\mathrm{mm}$, medium force $(200 \mathrm{~g})$ on left side were secured to hooks for retraction of premaxilla. The appliance is cemented to the premaxilla and palatal shelves [Fig.2(B)]. Immediately an elastic strap was placed to augment the retraction of the displaced premaxillary segment and corresponding soft tissue i.e. prolabium [Fig.2(C)]. The NiTi springs were left for one month after which they are replaced with continuous e-chain which was renewed every week.

Within the treatment period the oral hygiene was maintained by in-office irrigation and parental oral hygiene instructions. The whole procedure was carried out for two months [Fig.3], after which cheiloplasty was done. The appliance was removed and post-operative impressions were taken. Measurements on the pretreatment and posttreatment casts are mentioned in Table 1 [Fig.4].

The child gained normal weight and the parents were highly satisfied with improved facial appearance. The patient was followed for six months for positional changes in premaxilla [Fig.5].
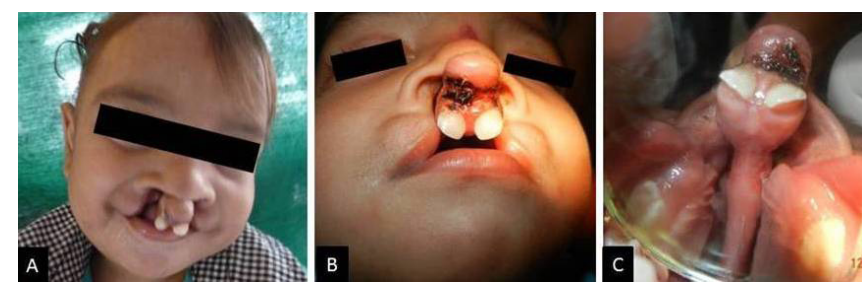

Fig.1:(A) Pre-treatment frontal view (B) Pretreatment sub-mento-vertex view (C) Pretreatment occlusal view.
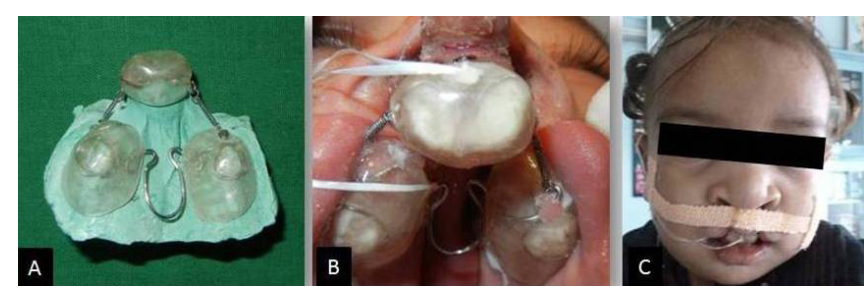

Fig.2:(A) Orthopedic appliance on cast (B) Appliance cemented in oral cavity (C) Elastic strap stabilizing the prolabium.
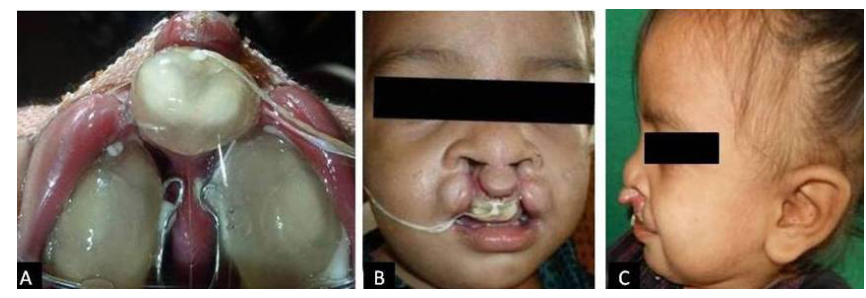

Fig.3:(A) Post-treatment occlusal view (B) Postretraction frontal profile (C) Post-retraction profile. 
Table 1: Cleft measurements on the pretreatment and post-treatment casts

\begin{tabular}{|l|l|l|l|}
\hline & $\begin{array}{l}\text { Pre - } \\
\text { treatment }\end{array}$ & $\begin{array}{l}\text { Post - } \\
\text { treatment }\end{array}$ & Net reduction in cleft \\
\hline Right cleft width & $20 \mathrm{~mm}$ & $10 \mathrm{~mm}$ & $10 \mathrm{~mm}$ \\
\hline Left cleft width & $25 \mathrm{~mm}$ & $15 \mathrm{~mm}$ & $10 \mathrm{~mm}$ \\
\hline
\end{tabular}

\section{Discussion}

Complete BCLP is the most severe form of the orofacial cleft subtypes with great variations in cleft anatomy. As described by Hodgkinson et al. (1986) the premaxilla and prolabial segment can either be protruded or rotated up under the nose or may appear to be missing [8]. Traditional method of treating these bilateral clefts was either by lip closure under tension, or a lip adhesion procedure followed by definitive lip repair and bone grafting for palatal defect. The use of maxillary orthopedics when compared to traditional methods undoubtedly brings the lip segments and maxillary arches to a proper anatomical alignment thus providing the ease in lip repair and periosteoplasty [9]. The guiding principle of PNAM is that the high level of estrogen at the time of birth correlates with the increased hyaluronic acid, which inhibits the linking of the cartilage intercellular matrix making newborns alar cartilage soft and plastic which can be manipulated with application of low grade constant forces [10-13]. Advantages for PSIO are considered including reduced complexity of future surgery, lesser scar, improved feeding, less need to secondary bone graft and improved speech [3]. Ross and Mc Namera (1994) described one possible benefit of presurgical infant orthopedics: if the maxillary segments are repositioned so that the lip segments are in closer apposition, then the lip surgery should be easier, enabling a more precise repair with less tension [14]. Though the age of the child is 19 months old we still planned for retraction of premaxilla in this particular case for enhanced esthetics and ease in surgical correction. Accordingly a modified appliance with basic

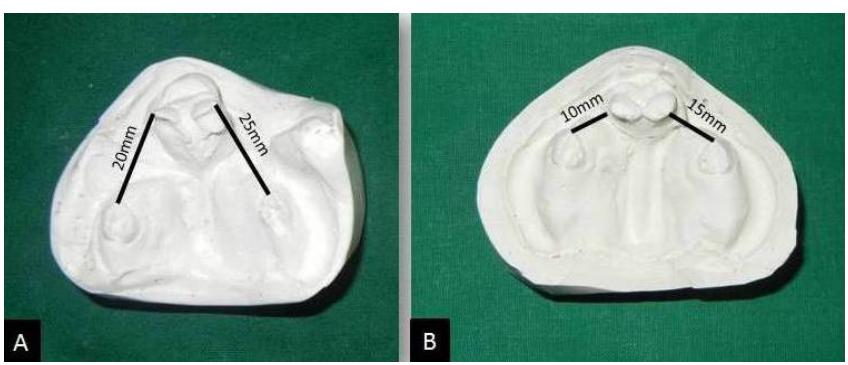

Fig.4:(A) Pre-treatment cast (B) Post-treatment cast.

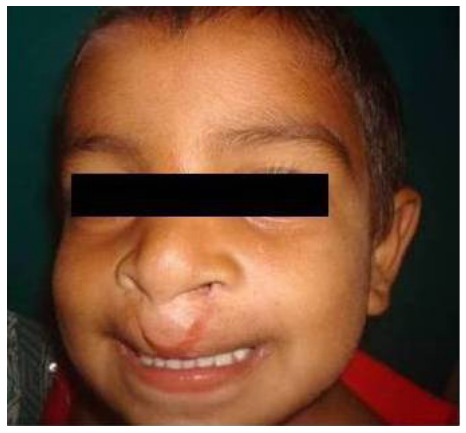

Fig.5: 6 months post-cheiloplasty frontal profile.

principles of design similar to Latham's appliance was fabricated. The advantages of this noninvasive appliance over Latham's appliance are mentioned in Table 2.

In BCLA patients, the palatal segment alignment and width is normal therefore palatal expansion as in Latham appliance causing distal repositioning of the premaxilla may induce a transverse maxillomandibular discrepancy [15]. As PNAM was performed late at 19 months, appliance fit was harmonious with alveolar process and direction of pull is well controlled with $\mathrm{NiTi}$ springs preventing excessive tipping of premaxilla. Nickel-titanium (NiTi) closed-coil springs were used in appliance because of its super elastic (SE) advantage - in comparison with steel springs, elastic chains or intraoral elastics, delivers nearly constant force in a wide deformation range and significant lower force degradation over time occurs for the 
constant extension than at conventional materials. These constant $\mathrm{NiTi}$ springs force is biologically acceptable than the intermittent high force delivery of the elastic modules [16].

Thus, the facilitation of lip and premaxilla reconstruction in difficult case makes presurgical orthopedics a productive technique because of reduced tension at the suture line and less need for soft tissue manipulation and thus eliminating the necessity for additional lip adhesion surgery and better augmentation of esthetics.

\section{Conclusion}

The case presented though not considered as ideal case of presurgical nasoalveolar molding was successfully managed with an appliance which is inexpensive, easy to fabricate, not requiring complicated laboratory techniques. Hence small amount time spent can do miracles in the long run was evident in this case.

\section{References}

1. Stellzig A, Basdra EK, Hauser C, Hassfeld S, Komposch G. Factors influencing changes in maxillary arch dimensions in unilateral cleft lip and palate patients until six months of age. Cleft Palate Craniofac J. 1999;36;304-309.

2. Ravichandra KS, Vijayaprasad KE, Vasa AAK, Suzan S. A new technique of impression making for an obturator in cleft lip and palate patient. J Ind Soc Ped Dent. 2010;28(4):31 1-316.

3. Soltan-Karimi V, Poorsattar Bejeh Mir A. Presurgical Naso-Alveolar Molding in a Neonate With Bilateral Cleft Lip and Palate: Report of a Case. J Compr Ped. 2012;3(2):8689.

4. McNeil CK. Orthodontic procedures in the treatment of congenital cleft palate. Dent Rec. 1950;70:126-132.

5. Georgiade NG, Latham RA. Maxillary arch
Table 2: Comparison of Latham appliance and Modified noninvasive appliance

\begin{tabular}{|c|c|}
\hline Traditional Latham appliance & Modified noninvasive appliance \\
\hline $\begin{array}{l}\text { Lack of affordability, feasibility, } \\
\text { accessibility. }\end{array}$ & Affordable, feasible and accessible. \\
\hline Invasiv & $\begin{array}{l}\text { Noninvasive: as the appliance is } \\
\text { cemented. }\end{array}$ \\
\hline $\begin{array}{l}\text { No surgical procedure in inserting } \\
\text { the appliance. }\end{array}$ & $\begin{array}{l}\text { Appliance fabricated and inserted } \\
\text { in conscious state of the child. }\end{array}$ \\
\hline Damage to tooth buds can occur. & No damage to tooth buds. \\
\hline $\begin{array}{l}\text { Chances of ulcerations, fungal } \\
\text { infection. }\end{array}$ & $\begin{array}{l}\text { With the ease of oral hygiene } \\
\text { maintenance, no chance of } \\
\text { ulceration and infection. }\end{array}$ \\
\hline
\end{tabular}

alignment in the bilateral cleft lip and palate infant, using the pinned coaxial screw appliance. Plast Reconstr Surg. 1975;56:52-60.

6. Millard DR, Latham RA. Improved primary surgical and dental treatment of clefts. Plast Reconstr Surg. 1990;86:856-871.

7. Rizwaan A S, Sujoy B, Rajlakshmi B, Atif K. Prosthetic Rehabilitation Of Cleft Compromised Newborns: A Review. J Clin Diagn Res. 2010;4:3632-3638.

8. Ricardo D. Bennun, Alvaro A. Figueroa: Dynamic Presurgical Nasal Remodeling in Patients With Unilateral and Bilateral Cleft Lip and Palate: Modification to the Original Technique. Cleft Palate-Craniofac J. 2006;43(6):639-648.

9. Berkowitz S. A comparison of treatment results in complete bilateral cleft lip and palate using a conservative approach versus Millard-Latham PSOT procedure. Semin Orthod. 1996;2:169184.

10. Matsuo K, Hirose T, Tomono T, Iwasawa $M$, Katohda S, Takahashi N, et al. Nonsurgical correction of congenital auricular deformities in the early neonate: a preliminary report. Plast Reconstr Surg. 1984;73:38-51.

11. Matsuo K, Hirose T. Nonsurgical correction of cleft lip nasal deformity in the early neonate. Ann Acad Med Singapore. 1988; 17:358-365.

12. Matsuo K, Hirose T, Otagiri T, Norose N. Repair of cleft lip with nonsurgical correction of nasal deformity in the early neonatal period. Plast 
Reconstr Surg. 1989;83:25-31.

13. Matsuo K, Hirose T. Preoperative non-surgical overcorrection of cleft lip nasal deformity. $\mathrm{Br} J$ Plast Surg. $1991 ; 44: 5-11$.

14. Grayson BH, Santiago PE, Brecht LE, Cutting CB. Presurgical Nasoalveolar molding in infants with cleft lip and palate. Cleft palate- Craniofac J. 1999;36(6):486-498.

15. Fukuyama E, OmuraS, Fujita K, Soma K, Torikai K. Excessive Rapid Palatal Expansion ewith
Latham Appliance for Distal Repositioning of Protruded Premaxilla in Bilateral Cleft Lip and Alveolus. Cleft Palate Craniofac J. 2006; 43(6):673-677.

16. Ales B, Libor B, Martin S, Tomas N, Jiri Z, Josef $\mathrm{H}$, Richard $\mathrm{P}$. Thermo-mechanical properties of $\mathrm{NiTi}$ closed coil springs force degradation and force regeneration over time, viscous properties. Acta Medica. 2013;56(2):41-46. 